\title{
Cerrahi branş hekimlerinin lokal anestezik kullanımı ve toksisitesine yaklaşımının değerlendirilmesi: Anket çalışması
}

\author{
The evaluation of the approach of local anesthetic use and toxicity of surgical \\ physicians: A questionnaire study
}

Duygu Demiröz Aslan (D) Ayşe Gül Ferlengez

İstanbul Eğitim ve Araştırma Hastanesi, Anesteziyoloji ve Reanimasyon Kliniği, İstanbul, Türkiye

Öz

Amaç: Lokal anestezik (LA) ilaçlar günümüzde sıkça kullanılmaktadır. Yanlış uygulama şekli ve dozu toksisitesinin en sık nedenleridir. Son yıllarda lipit emülsiyonu infüzyonlarının standart resüsitasyon uygulamalarına yanıt vermeyen toksisite durumlarında başarıyla kullanıldığı bildirilmektedir. Bu çalışmanın amacı, cerrahi branş hekimleri LA'ler ve lokal anestezik toksisite sendromu (LATS) hakkında bilgilerini incelemek, toksisite ve tedavisi hakkında farkındalığı arttırmaktır.

Gereç ve Yöntem: Çalışmamıza hastanemizde çalışan anestezistler dışındaki cerrahi branş hekimleri dahil edildi. Hekimlere yaş, cinsiyet, branş, uzmanlık yılı ve en çok tercih ettikleri LA, uygulama yolu, toksisiteyi önlemek için uyguladıkları yöntemler, toksisitenin erken ve geç dönem bulguları ve tedavisini içeren 14 soru yöneltildi. 108 hekime anket soruları yöneltildi ve tüm sorulara cevap verilmediği için 17'si çalışma dışı bırakılarak 91 anket sonucu değerlendirildi.

Bulgular: Çalışmamıza 9 branş hekimi katıldı. En yüksek katııı \%44 oranı ile Genel Cerrahi hekimleri olup, hekimlerin \%68'i uzmandı ve meslekte çalışma yılı 10 yıldan fazla olanlar \%31,9 oranıyla en yüksekti. En çok tercih edilen lokal anesteziğin lidokain olduğu görüldü. Haftada ikiden fazla kullanımın en yaygın olduğu ve en sık uygulama şeklinin subkutan/intramusküler enjeksiyon olduğu görüldü. \%78'i uygun doz ilaç kullanıyordu. Toksisitesinin erken dönem bulguları sorusuna, hekimler en sık alerji derken, geç dönem bulgularında ise en sık kardiyak arrest cevabını verdi. Tedavisinde ise semptomatik tedavi ilk sırayı aldı. LA toksisitesinde lipit kullanımı sorgulandığında \%61,6 hekim hiç duymadığını belirtti.

Sonuç: LA uygulayan cerrahi hekimlerin LATS bulguları, semptomları ve toksisite tedavi yöntemleri hakkında yeterli bilgi sahibi olmadıkları belirlendi ve hasta güvenliğini sağlamada ve komplikasyonları önlemede LATS bilinmesi ve tedavisinin önemli olduğunu düşünmekteyiz.

Anahtar Sözcükler: Lokal anestezikler, toksisite, anket.

\begin{abstract}
Aim: Local anesthetic (LA) drugs are used frequently today. Incorrect administration and dose are the most common causes of toxicity. In recent years, it has been reported that lipid emulsion infusions have been used successfully in toxicity states that do not respond to standard resuscitation practices. The purpose of this study is to examine the knowledge of surgical physicians about LAs and LATS (local anesthetic toxicity syndrome) and to raise awareness about toxicity and treatment.

Materials and Methods: Surgical physicians other than anesthetists working in our hospital were included in our study. We asked 14 questions including age, gender, branch, specialty year, their preferred $L A$ and method, methods to prevent toxicity, early and late findings and treatment of toxicity. Survey questions were directed to 108 physicians and 17 of them were excluded from the study because all questions were not answered, 91 survey results were evaluated.
\end{abstract}

\footnotetext{
Sorumlu yazar: Ayşe Gül Ferlengez

İstanbul Eğitim ve Araştırma Hastanesi, Anesteziyoloji ve

Reanimasyon Kliniği

E-posta: aysegulsoylemez@yahoo.com

Başvuru Tarihi: 12.03.2020 Kabul Tarihi: 03.06.2020
} 
Results: 9 physicians attended our study. The highest participation was General Surgery with a rate of $44 \%, 68 \%$ of them were specialists, and those with more than 10 years of work in the profession were the highest with $31.9 \%$.It was found that the most preferred LA was lidocaine. It was observed that more than two uses per week were most common and the most common form of administration was subcutaneous / intramuscular injection. $78 \%$ were using appropriate doses of drugs. The question of early signs of toxicity was the most frequent allergy, while in the late findings, cardiac arrest was the most common. In the treatment, symptomatic treatment took the first place. When lipid use was questioned in LA toxicity, $61.6 \%$ of physicians stated that they had never heard of it.

Conclusion: It was determined that surgical physicians who performed LA did not have sufficient information about LATS findings, symptoms and toxicity treatment methods, and we think that knowing and treating LATS is important in ensuring patient safety and preventing complications.

Keywords: Local anesthetics, toxicity, questionnaire.

\section{GíRiş}

Lokal anestezik (LA) nöronal hücrelerin membranında sodyum geçişini engelleyerek motor ve duyu bloğu oluşturmaktadır (1). LA birçok kullanım avantajı olup bunun yanında ciddi komplikasyonlara da neden olabilmektedir (2).

Lokal anestezik ajanın proteine bağlanabilme özelliği, yağda çözünürlüğü, $\mathrm{pH}$, çözünürlük sabiti ve enjeksiyon yapılan alanın vaskülaritesi gibi özellikler, anestezik etkiyi ve sistemik toksisiteyi etkilemektedir (1). Lokal anesteziye bağlı komplikasyonlar klinik olarak genellikle ilk $5 \mathrm{dk}$. içerisinde gelişmektedir. Lokal anestezi toksisite sendromu (LATS) nadir görülen ölümcül bir komplikasyonudur. Hedef organ genellikle santral sinir sistemi (SSS) ve kardiyovasküler sistem (KVS)'dir. Illk olarak baş dönmesi ve tinnitus gibi SSS bulguları ortaya çıkar (3). Daha sonra plazma LA konsantrasyonu artışı ile birlikte aritmi ve derin kardiyovasküler kollapsa kadar ilerleyen döneme girilir ve kardiyak arreste varabilen etkiler oluşur (4).

Toksisite tedavisinde, hava yolu kontrolünün sağlanması, konvülsiyon gibi semptomların tedavisi ve son yıllarda kardiyak toksisitenin tedavisinde lipit solüsyonlarının kullanılması önerilmektedir (5). Çalışmamızda LA kullanımına bağlı nadir fakat ölümcül olabilen komplikasyonları önleme, fark etme ve toksisite tedavisinin önemini vurgulamayı amaçladık.

\section{Gereç ve Yöntem}

Sağlık Bilimleri Üniversitesi İstanbul Eğitim ve Araştırma Hastanesi etik kurulundan karar no:1700 15.02.2019 tarihli etik kurul onayı alındıktan sonra, benzer çalışmalar incelenerek 14 sorudan oluşan bir anket formu hazırlandı. Anlaşılırlığını ve cevap süresini belirlemek üzere 10 hekim tarafından ön uygulama yapıldı.
Çalışma hakkında katılımcılardan bilgilendirilmiş onam alınarak, ortalama 10 dakikada cevaplanabilecek, 14 sorudan oluşan anket soruları (Tablo-1) hastanemizde çalışmakta olan anestezistler dışındaki cerrahi branş hekimlerine yazılı olarak dağıtıldı. Hekimlere yaş, cinsiyet branş uzmanlık yılı ve en çok tercih ettikleri LA, uygulama yolu, daha önceden LA toksisitesiyle karşılaşmış olup olmadıkları, LA toksisitesini önlemek için uyguladıkları yöntemler, LA toksisitenin erken ve geç dönem bulgularını, toksisite tedavisini içeren 14 soru yöneltildi. 108 katılımcıdan 17'si soruları tam olarak cevaplamadığı için çalışma dışı bırakıldı ve 91 katılımcının anket sonuçları değerlendirildi.

\section{Istatistiksel Analiz}

İstatistik testleri için IBM SPSS for Windows, version 22.0 (IBM statistics for Windows version 22, IBM Corparation, Armonk, New York, United States) programı kullanıldı. Veriler ortalama + standart sapma ile ifade edildi. Numerik değişkenler ortalama \pm standart sapma olarak, kategorik veriler ise sayısal değer ve yüzde olarak değerlendirildi.

\section{Bulgular}

Ankete toplam 108 hekimi katıldı. Katılımcılardan 17 hekim eksik cevaplar verdiği için çalışmadan çıkarılırken, 91 hekimin cevapları değerlendirmeye alındı. Katılımcıların yaş ortalaması 37,7 \pm 5 yıl olup 73'ü erkek,18'i kadın hekimdi. 62 uzman, 29'u asistan hekim olup branş dağılımı Genel Cerrahi \%44, Kadın Hastalıkları ve Doğum \%22, Ortopedi ve Travmatoloji \%12, Beyin ve Sinir Cerrahisi \%3, Kulak Burun Boğaz \%1,8, Üroloji $\% 2$, Plastik Cerrahi \%2, diğer branşlar \%13,2 idi. Çalışma yılı dağılımına göre 10 yıldan fazla olan hekim grubu \%31,9 oranıyla en yüksek oranda olup 2-5 yıl arası \%29,6 oranıyla ikinci sırada yer almaktaydı (Tablo-2). 
Tablo-1. Uygulanan anket formu.

\begin{tabular}{|c|c|c|}
\hline Soru No & Soru & Cevap Seçenekleri \\
\hline 1 & Yaşınız? & \\
\hline 2 & Cinsiyetiniz nedir? & $\begin{array}{l}\text { Kadın } \\
\text { Erkek }\end{array}$ \\
\hline 3 & Unvanınız nedir? & $\begin{array}{l}\text { Uzman hekim } \\
\text { Asistan hekim }\end{array}$ \\
\hline 4 & Branşınız nedir? & $\begin{array}{l}0-6 \text { ay } \\
6-12 \text { ay }\end{array}$ \\
\hline 5 & Çalışma süresiniz nedir? & $\begin{array}{l}1-2 \text { yıl } \\
2-5 \text { yıl } \\
5-10 \text { yıl } \\
10 \text { yıl ve üzeri } \\
\text { Bupivakain }\end{array}$ \\
\hline 6 & $\begin{array}{l}\text { En çok tercih ettiğiniz lokal anestezik nedir? (birden çok cevaplı } \\
\text { soru) }\end{array}$ & $\begin{array}{l}\text { Prilokain } \\
\text { Lidokain } \\
\text { Diğerleri } \\
\text { Her gün } \\
\text { Haftada ikiden fazla }\end{array}$ \\
\hline 7 & Lokal anestezik kullanım sıklığınız nedir? & $\begin{array}{l}\text { Haftada bir } \\
\text { Ayda bir } \\
\text { Yılda } 3 \\
\text { Subkutan/intramüsküler }\end{array}$ \\
\hline 8 & $\begin{array}{l}\text { En sık tercih ettiğiniz lokal anestezik uygulama şekli nedir? } \\
\text { (birden çok cevaplı soru) }\end{array}$ & $\begin{array}{l}\text { Topikal } \\
\text { İntravenöz } \\
\text { İntranazal } \\
\text { Diğer }\end{array}$ \\
\hline 9 & Daha önceden lokal anestezik toksisitesiyle karşılaştınız mı? & $\begin{array}{l}\text { Evet } \\
\text { Hayır } \\
\text { Monitorizasyon }\end{array}$ \\
\hline 10 & $\begin{array}{l}\text { Lokal anestezik toksisitesini önlemek için hangi önlemleri } \\
\text { alıyorsunuz? (birden çok cevaplı soru) }\end{array}$ & $\begin{array}{l}\text { Uygun dozlarda kullanma } \\
\text { Adrenalin ile test dozu } \\
\text { Aralıklı enjeksiyon } \\
\text { Aspirasyon } \\
\text { Allerji } \\
\text { Hipotansiyon }\end{array}$ \\
\hline 11 & $\begin{array}{l}\text { Lokal anestezik toksisitenin erken dönem bulguları nelerdir? } \\
\text { (birden çok cevaplı soru) }\end{array}$ & $\begin{array}{l}\text { Anaflaksi } \\
\text { Aritmi } \\
\text { Dilde metalik tat } \\
\text { Tinnitus } \\
\text { Diğer } \\
\text { Kardiyak arrest } \\
\text { Hepatotoksisite }\end{array}$ \\
\hline 12 & $\begin{array}{l}\text { Lokal anestezik toksisitenin geç dönem bulguları nelerdir? } \\
\text { (birden çok cevaplı soru) }\end{array}$ & $\begin{array}{l}\text { Şuur kaybı } \\
\text { İskemi } \\
\text { Enfeksiyon } \\
\text { Diğer } \\
\text { Semptomatik tedavi } \\
\text { Kardiyopulmuner }\end{array}$ \\
\hline 13 & $\begin{array}{l}\text { Lokal anestezik toksisitenin tedavisi nelerdir? (birden çok } \\
\text { cevaplı soru) }\end{array}$ & $\begin{array}{l}\text { resusitasyon } \\
\text { Antihistaminik ilaç } \\
\text { tedavisi } \\
\text { Metilen mavisi } \\
\text { \%20 Lipit solüsyonu } \\
\text { Hiç duymadım } \\
\text { Duydum ama }\end{array}$ \\
\hline 14 & \%20 Lipit solüsyonu hakkında ne biliyor musunuz? & $\begin{array}{l}\text { hatırlamıyorum } \\
\text { Kullanım alanı ve şeklini } \\
\text { biliyorum }\end{array}$ \\
\hline
\end{tabular}


Tablo-2. Ankete katılan hekimlerin demografik verileri.

\begin{tabular}{ll}
\hline & $\mathbf{n}(\%)$ \\
\hline Yaş (yıl) & $37,7 \pm 0,5$ \\
Cinsiyet & $18(19,8)$ \\
Kadın & $73(80,2)$ \\
Erkek & \\
Unvan & $62(68,1)$ \\
Uzman hekim & $29(31,9)$ \\
Asistan hekim & \\
Çalışma süresi & $3(3,3)$ \\
$0-6$ ay & $8(8,8)$ \\
$6-12$ ay & $8(8,8)$ \\
$1-2$ yıl & $27(29,6)$ \\
$2-5$ yıl & $16(17,6)$ \\
$5-10$ yıl & $29(31,9)$ \\
10 yıl ve üzeri & \\
\hline
\end{tabular}

Tablo-3. Hekimlerin lokal anestezik tercihi, kullanım sıklığı ve yolu.

\begin{tabular}{ll}
\hline En çok tercih edilen lokal anestezik (birden çok cevaplı soru) & $\mathbf{n}(\%)$ \\
\hline Bupivakain & $18(19,8)$ \\
Prilokain & $50(54,9)$ \\
Lidokain & $54(59,3)$ \\
Diğerleri & $1(1,1)$ \\
Lokal anestezik kullanım sıklığı & \\
Her gün & $22(24,2)$ \\
Haftada ikiden fazla & $42(46,1)$ \\
Haftada bir & $19(20,9)$ \\
Ayda bir & $6(6,6)$ \\
Yılda 3 & $2(2,2)$ \\
Lokal anestezik kullanım yolu (birden çok cevaplı soru) & \\
Subkutan/intramüsküler & $87(95,6)$ \\
Topikal & $43(47,2)$ \\
İntravenöz & $2(2,2)$ \\
İntranazal & $1(1,1)$ \\
Diğer & $0(0)$ \\
\hline
\end{tabular}

En sık tercih edilen LA sorusuna \%59,3 lidokain, $\% 54,9$ prilokain cevabı verildiği görüldü. LA kullanım sıklık oranları haftada ikiden fazla \%46,1, haftada bir \%20,9, her gün \%24,2 olarak hesaplandı. Lokal anestezik uygulama yönteminin sorgulandığında en sık subkutan/intramusküler $(\% 95,6)$, ikinci sıklıkla topikal uygulamanın $(\% 47,2)$ tercih edildiği görüldü (Tablo-3).

Hekimlerin LA toksisitesiyle ilişkili sorularda ise $\% 7,7$ 'sinin LATS ile karşılaştığı, toksisiteyi önlemede yapılan önlemlerde ise \%78 uygun doz kullanımı, \%39,6 monitorizasyon, \%35,2 aralıklı enjeksiyon en sık kullanılan teknikler olduğu görüldü. LATS'nin erken klinik bulguları sorgulandığında \%60,4 alerji, \%58,2 hipotansiyon, \%42,3 anaflaksi, \%38,5 dilde metalik tat, \%37,4 aritmi ve \%20,9 tinnitus cevabının verildiği görüldü. Geç dönem bulgularında \%52,7 kardiyak arrest, $\% 49,4$ hepatotoksisite, \%34,1 iskemi ve \%34,1 şuur kaybı cevapları alındı (Tablo-4).

Lokal anestezi toksisite sendromu tedavisi sorgulandığında \%78 semptomatik, \%50,5 antihistaminik, \%48,4 kardiyopulmoner resusitasyon, $\% 25,3$ lipit solüsyonu, $\% 15,4$ ise metilen mavisi seçeneğinin tercih edildiği görüldü. Lipit tedavisi sorgulandığında \%61,6 hekimin hiç duymadığı ve sadece \%6,6 hekimin kullanım alanı ve dozu hakkında bilgi sahibi olduğu görüldü (Tablo-5). 
Tablo-4. Hekimlerin lokal anestezik toksisitesine yaklaşımı.

\begin{tabular}{|c|c|}
\hline Daha önceden lokal anestezik toksisitesiyle karşılaştınız mı? & n (\%) \\
\hline Evet & $7(7,7)$ \\
\hline Hayır & $84(92,3)$ \\
\hline \multicolumn{2}{|c|}{$\begin{array}{l}\text { Lokal anestezik toksisitesini önlemek için hangi önlemleri alıyorsunuz? } \\
\text { (birden çok cevaplı soru) }\end{array}$} \\
\hline Monitorizasyon & $36(39,6)$ \\
\hline Uygun dozlarda kullanma & $71(78,0)$ \\
\hline Adrenalin ile test dozu & $5(5,5)$ \\
\hline Aralıklı enjeksiyon & $32(35,2)$ \\
\hline Aspirasyon & $12(13,2)$ \\
\hline \multicolumn{2}{|c|}{ Lokal anestezik toksisitenin erken dönem bulguları nelerdir? (birden çok cevaplı soru) } \\
\hline Alerji & $55(60,4)$ \\
\hline Hipotansiyon & $53(58,2)$ \\
\hline Anaflaksi & $43(42,3)$ \\
\hline Aritmi & $34(37,4)$ \\
\hline Dilde metalik tat & $35(38,5)$ \\
\hline Tinnitus & $19(20,9)$ \\
\hline Diğer & $4(4,4)$ \\
\hline \multicolumn{2}{|c|}{ Lokal anestezik toksisitenin geç dönem bulguları nelerdir? (birden çok cevaplı soru) } \\
\hline Kardiyak arrest & $48(52,7)$ \\
\hline Hepatotoksisite & $45(49,4)$ \\
\hline Şuur Kaybı & $31(34,1)$ \\
\hline İskemi & $31(34,1)$ \\
\hline Enfeksiyon & $12(13,2)$ \\
\hline Diğer & $11(12,1)$ \\
\hline
\end{tabular}

Tablo-5. Lokal anestezik toksisitesi tedavisi, lipit solüsyonu.

\begin{tabular}{ll}
\hline Lokal anestezik toksisitenin tedavisi nelerdir? (birden çok cevaplı soru) & $\mathbf{n}(\%)$ \\
\hline Semptomatik tedavi & $71(78,0)$ \\
\hline Kardiyopulmoner resusitasyon & $44(48,4)$ \\
\hline Antihistaminik ilaç tedavisi & $46(50,5)$ \\
Metilen mavisi & $14(15,4)$ \\
\%20 Lipit solüsyonu & $23(25,3)$ \\
\%20 Lipit solüsyonu hakkında ne biliyorsunuz? & \\
Hiç duymadım & $56(61,6)$ \\
Duydum ama hatırlamıyorum & $28(30,8)$ \\
Kullanım alanı ve şeklini biliyorum & $6(6,6)$ \\
\hline
\end{tabular}




\section{Tartışma}

Lokal anestezik kullanımının nadir görülen ancak ölümcül olabilen komplikasyonu LATS olup toksisitesinin belirtilerinin bilinmesi tedaviye erken başlamak, kardiyak toksisiteyi önlemek ve ölüm dahil olmak üzere tüm olumsuz sonuçlardan kaçınmak için önemlidir (6).

Literatürde Ortopedi ve Travmatoloji ve Acil Tıp Kliniğine ait çok sayıda LATS olgusu bulunmaktadır $(7,8)$. Çalışmamızda LA'ların yüksek oranda kullanımının Genel Cerrahi hekimlerinde görüldüğünü belirledik. Bu sonucun, tek merkezli olan çalışmamıza katılan genel cerrahi hekim sayının daha fazla olmasından kaynaklandığını düşünmekteyiz.

Lokal anestezik toksisite riskini azaltmak için, kullanılacak dozu sınırlandırmak, kateter yerleştirirken kullanılacaksa ultrason veya direkt görüntüleme yöntemlerini tercih etmek, test dozu uygulama, aralıklı ilaç enjeksiyonu, sık aspirasyon (yaklaşık $3 \mathrm{ml}$ ) ve mümkünse herhangi bir belirti veya semptom olup olmadığını belirlemek için hastayla sözlü teması sürdürmek gibi yöntemler önerilmektedir $(9,10)$. Ayrıca LA solüsyonuna epinefrin eklenmesi LA'nın plazmaya girişinin azaltarak yüksek dozların daha güvenli bir şekilde uygulanmasını sağlamaktadır (11). Çalışmamızda hekimlerin toksisiteden kaçınmak için büyük çoğunluğunun uygun doz kullanımını tercih ettiğini ve diğer yöntemlerin yeterli düzeyde uygulanmadığını gördük.

Lokal anestezi toksisite sendromunda klinik belirtiler genellikle 0-5 dakika içerisinde gelişir ve tinnitus, sersemlik, dudak çevresinde uyuşukluk, görme ve işitmede bozulma, şuur değişiklikleri ile başlar ve toksisitenin şiddetine göre nöbet, aritmi, solunum arresti, hipotansiyon ve şok görülebilir (12). Çalışmamızda hekimlerin LATS'nin erken dönem ve geç dönem belirtileri hakkında yeterli bilgi düzeyine sahip olmadığı sonucuna ulaştık.

Anestezi kılavuzlarında LATS gelişen olgularda hava yolu kontrolü, $100 \%$ oksijen ile ventilasyon, konvülzyonun durdurulması ve gerektiği taktirde kardiyopulmoner resüsitasyon ile birlikte \%20'lik intravenöz lipit (IVL) kullanımı üzerinde önemle durulmaktadır. Hava yolu yönetiminde; optimal oksijenizasyon ve ventilasyon ile hipoksi ve asidoz önlenirken, kardiyovasküler depresyon ve nöbetleri ortadan kaldırabilmektedir. (13, 14). Lokal anestezi toksisite sendromu durumunda, \%20 IVL'nin 1,5 ml/kg bolus şeklinde verilip 0,25 $\mathrm{ml} / \mathrm{kg} /$ dakika infüzyon olarak idamesi önerilmektedir, belirtilerin düzelmemesi durumunda bolus dozun iki kez daha tekrarlanması ve 10 $\mathrm{ml} / \mathrm{kg}$ maksimumu doza kadar uygulanması önerilmektedir (15). Foxall ve ark. Lokal anestezik toksisitesi gelişen bir hastaya arrest gelişmeden önce $\mathrm{iVL}$ infüzyonu uygulandığında kalp ritminin sinüse döndürülebildiğini bildirmiştir (16). Marwick ve ark. da uygun dozda iVL tedavisi alan bir hastada kardiyovasküler kollapsın geri döndüğünü gözlemlemiş ve iVL'nin erken dönemde başlanması gerektiğini vurgulamıştır (17). Çalışmamızda hekimlerin LATS tedavisinde semptomatik tedavi üzerinde durduklarını, IVL tedavisi hakkında yeterli bilgiye sahip olmadıklarını gördük.

Prilokain metabolitleri (O-tolidin deriveleri) yüksek doz kullanıma bağlı birikebilir ve hemoglobini methemoglobine dönüştürebilir. Lokal anestezik spreylerinde bulunan benzokain de methemoglobinemiye neden olabilir (18). Methemoglobineminin tedavisinde metilen mavisi (1-2 $\mathrm{mg} / \mathrm{kg} \% 1^{\prime}$ lik solüsyondan 5 dakikadan uzun sürede) intravenöz olarak uygulanmaktadır (12). Çalışmamızda hekimlerin LA arasında prilokain kullanım tercihi yüksek iken yeterli düzeyde toksisite tedavisi hakkında bilgi sahibi olmadıkları görüldü.

\section{Sonuç}

Çalışmamızda sık LA kullanmakta olan hekimlerin toksisiteyi önlemek için gerekli olan "uygun kullanım dozu" önlemini aldığını, fakat diğer önlemler ve toksisitenin erken ve geç dönem bulguları ve tedavisi hakkında yeterli bilgiye sahip olmadıkları sonucuna ulaştık. Lokal anestezik sistemik toksisite nadir ancak ölümcül olabilmektedir. LA uygulayan cerrahi hekimlerin güvenli LA kullanımı ve LATS bulguları, semptomları ve toksisite tedavi yöntemleri hakkında yeterli bilgi sahibi olmalarının hasta güvenliğini sağlamada önemli olduğunu düşünmekteyiz.

\section{Çıkar çatışması}

Yazarlar arasında çıkar çatışması bulunmamaktadır. 


\section{Kaynaklar}

1. Ökten F, Hasdoğan M, Tarhan A. Bupivakain kardiyotoksisitesi ne derece önemlidir? Anestezi Dergisi 2010; 18: $189-93$.

2. El-Boghdadly K, Chin KJ. Local anesthetic systemic toxicity: Continuing Professional development. Can J Anesth. 2016; 63: 330-49.

3. Dickerson DM, Apfelbaum JL. Local anesthetic systemic toxicity. Aesthet Surg J. 2014; 34: 1111-9.

4. Fettiplace MR, Weinberg G. Past, present, and future of lipid resuscitation therapy. JPEN J Parenter Enteral Nutr. 2015; 39: 72-83.

5. Neal JM, Mulroy MF, Weinberg GL. American Society of Regional Anesthesia and Pain Medicine. American Society of Regional Anesthesia and Pain Medicine checklist for managing local anesthetic systemic toxicity: 2012 version. Reg Anesth Pain Med. 2012; 37: 16-8.

6. Guideline for care of the patient receiving local anesthesia. In: Guidelines for Perioperative Practice. Denver, CO: AORN, Inc; 2017: 617-28.

7. Turhan SÇ, Özçelik M, Koza EA, Adaklı B, Ökten F. Aksiller brakial pleksus blokajı sonrası gelişen levobupivakain toksisitesi. Turkiye Klinikleri J Anest Reanim. 2014; 12: 110-3.

8. Tierney KJ, Murano T, Natal B. Lidocaine-induced cardiac arrest in the emergency department: effectiveness of lipid therapy. J Emerg Med. 2016; 50: 47-50.

9. Mulroy MF, Norris MC, Liu SS. Safety steps for epidural injection of local anesthetics: review of the literature and recommendations. Anesth Analg. 1997; 85: 1346-56.

10. Noble KA. Local anesthesia toxicity and lipid rescue. J Perianesth Nurs. 2015; 30 (4): 321-35.

11. Bailard NS, Ortiz J, Flores RA. Additives to local anesthetics for peripheral nerve blocks: evidence, limitations, and recommendations. Am J Health Syst Pharm. 2014; 71 (5): 373-85.

12. Lokal anestezikler. Editörler: Morgan E, Mikhail MS, Murray MJ. Çeviri Editörleri: Tulunay M, Cuhruk H. Klinik Anesteziyoloji (Clinical Anesthesia). 4. Baskı. Güneş Tıp Kitapevleri- Ankara; 2008. 263-76.

13. Neal JM, Mulroy MF, Weinberg GL. American society of regional anesthesia and pain medicine checklist for managing local anesthetic systemic toxicity: 2012 version. Reg Anesth Pain Med. 2012; 37: 816-7.

14. Cave G, Harrop-Griffiths W, Harbey M, Meek T, Picard J, Short T, et al. AAGBI Safety Guideline: Management of Severse Local Anaesthetic Toxicity. Assoc Anaesth. 2010; 1-6.

15. El-Boghdadly K, Chin KJ. Local anesthetic systemic toxicity: Continuing Professional development. Can J Anesth. 2016; 63: 330-49.

16. Foxall G, McCahon R, Lamb J, et al. Levobupivacaine-induced seizures and cardiovascular collapse treated with Intralipid®.Anaesthesia. 2007; 62: 516-8.

17. Marwick PC, Levin Al, Coetzee AR. Recurrence of cardiotoxicity after lipid rescue from bupivacaine-induced cardiac arrest. Anesth Analg. 2009; 108 (4): 1344-6.

18. Becker DE, Reed KL. Essentials of local pharmacology. Anesth Prog. 2006; 53: 98-108. 